\title{
Price Effect of Building Energy Ratings in the Dublin Residential Market
}

Sarah Stanley, Ronan C. Lyons and Sean Lyons

\author{
TEP Working Paper No. 0415
}

June 2015

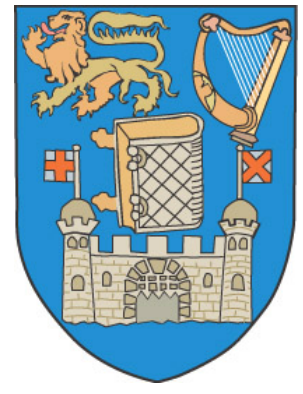

Trinity Economics Papers

Department of Economics

Trinity College Dublin 


\title{
The Price Effect of Building Energy Ratings in the Dublin Residential Market
}

Sarah Stanley*, Economic and Social Research Institute, Dublin; Sustainable Energy Authority of Ireland

Ronan C. Lyons, Department of Economics, Trinity College Dublin; Spatial Economics Research Centre, London School of Economics

Sean Lyons, Economic and Social Research Institute, Dublin; Department of Economics, Trinity College Dublin

*Corresponding author. Email address for correspondence: sstanleyireland@gmail.com

\begin{abstract}
This paper is an empirical study of the relationship between the energy performance rating of residential homes in the Dublin market between 2009 and 2014 and their market prices, controlling for building type, size, age, and location. Initial results suggest that energy efficiency has a significant, positive relationship with list price. A 50-point improvement in the Energy Performance Indicator $\left(\mathrm{kWh} / \mathrm{m}^{2} / \mathrm{yr}\right)$ is associated with a $1.5 \%$ higher list price. Alternatively, using the Building Energy Rating metric, a one-point improvement in the 15-point scale from $\mathrm{G}$ to A1 yields a list price increase of $1 \%$. This mirrors findings for efficiency price premiums on a nationwide basis from Hyland et al. (2013). We also find that it is important to include controls for the age of the dwelling to avoid biased energy efficiency estimates in the hedonic model.
\end{abstract}

Key words: domestic building energy ratings, hedonic valuation, Ireland 


\section{Introduction}

In an era of environmental awareness and concerted action toward sustainable energy management, energy efficiency is a key challenge. Buildings account for $40 \%$ of energy consumption in Europe (EC 2010) and residential homes contribute to around one sixth of emissions globally (IEA 2013). Promisingly, small improvements to the structure of buildings (such as greater insulation or replacing inefficient heating systems) can have a significant impact on their energy performance. Despite the environmental benefits and energy savings that can be gained from more energy efficient homes, evidence of buyer appreciation of the value of energy efficiency and domestic investment in efficiency measures to boost property values has been limited. Supplementary literature has begun to emerge on willingness to pay for energy efficiency (Banfi et al. 2008; Brounen \& Kok 2011; Cajias \& Piazolo 2013; Cerin et al. 2014; DECC 2013; EC 2013a; Hyland et al. 2013; McLean et al. 2013; Popescu et al. 2012), whether energy savings are considered in buying decisions (Amecke 2012; Murphy 2014), and if financing should stem from private or public sources (Allcot \& Greenstone 2012; EC 2013b; Gilllingham et al. 2009, 2012). This paper adds to this literature, providing hedonic value estimates for residential energy efficiency in the Dublin region of Ireland over the period 2009-2014. We use a variety of categorical and continuous variables to represent energy efficiency of dwellings and find a broadly consistent pattern of effects whereby better efficiency attracts a higher valuation. We also find that it is important to include controls for the age of the dwelling, because omitting this characteristic can lead to biased estimates of the energy efficiency effect.

\subsection{Policy Background}

The United Nations Framework Convention on Climate Change (UNFCCC), established in 1992, initiated an international framework for negotiating greenhouse gas emissions targets for participating countries in an effort to stabilise global warming. The European Union is among 192 parties that are currently signatories of the Kyoto Protocol, an extension of the UNFCCC, which has set an internationally binding target to reduce emissions by at least $18 \%$ compared to 1990 levels by 2020 (UNFCCC 2012). International commitment towards reducing greenhouse gas emissions was most recently reinforced by an agreement by the G7 (Canada, France, Germany, Italy, Japan, the United Kingdom, and the United States) to decarbonise the global economy by the end of the century (G8 Information Centre 2015). In conjunction with carbon and renewable policies, the European Union's Energy Efficiency Directive (2012/27/EU) aims for a 20\% reduction in energy demand in the European Union as a whole by 2020. One of the main policy tools for reducing energy consumption in the buildings sector and advancing awareness of the energy performance of buildings are Energy Performance Certificates (EPCs). EPCs provide a benchmark for ranking buildings based on their predicted energy consumption per square metre and the associated $\mathrm{CO}_{2}$ emissions. Since the 1990s, a combination of voluntary and mandatory EPC schemes across residential, commercial and/or public buildings have emerged in countries such as Australia (NatHERS, Green Star), Russia (Energy Passport), the United States (LEED, Energy Star, HERS Index), Japan (CASBEE), and Singapore (Energy Smart, BCA Green Mark). In the European Union, the 2002 EU Directive on the Energy Performance of Buildings (EPBD 2002/91/EC, recast 2010) introduced a mandatory requirement for member states to provide specific information on a building's energy performance and recommendations for energy saving measures to prospective purchasers and tenants in property transactions. Despite a possible fine of up to $€ 5,000$ issued for non-compliance, rates of compliance across Europe prior to the 
recast Directive have been limited by problems with enforcement and access to reliable data (BPIE 2014; IEA 2010; The European Parliament the Council of the EU 2010a). From 2013 onwards, amongst other things, the recast EPBD ensures that all properties advertised for sale or for rental, excluding certain buildings such as protected structures, include an official energy certificate (The European Parliament the Council of the EU 2010b).

\section{Previous Research}

The majority of empirical evidence on the impact of energy certificates on building prices supports the assumption that people are willing to pay extra for more efficient properties in both the commercial and residential sector. Studies in the commercial sector, primarily in the United States, suggest that green offices acquire a price premium from 13\% to 30\% (Chegut et al. 2011; Eichholtz et al. 2010, 2013; Fuerst \& McAllister 2011a, 2011b; Miller et al. 2008; Pivo \& Fisher 2010; Wiley et al. 2008;). Similarly positive results of a lower magnitude are observed in the residential sector. Figure 1 displays price premiums between $2 \%$ and $10 \%$ in A, B and C-rated homes and price discounts in lower rated homes when compared to D-rated properties in the Netherlands and in Ireland (Brounen \& Kok 2011; Hyland et al. 2013). The letter scale from $A$ to $G$ in Figure 1 reflects the annual energy use in specific terms (kilowatt hours used per square metre or kilograms of $\mathrm{CO}_{2}$ per square metre) where $\mathrm{A}$ is the most energy efficient and $\mathrm{G}$ is the least energy efficient.

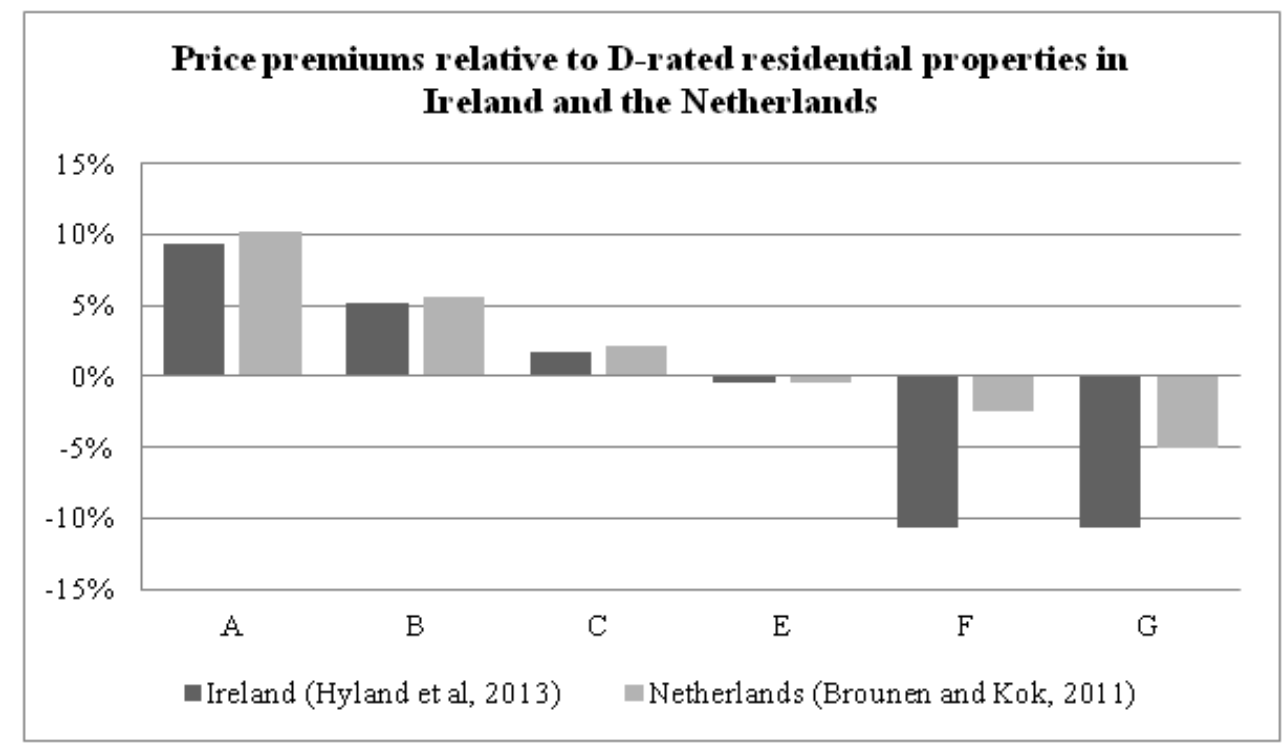

Figure 1: Price premiums relative to D-rated residential properties in Ireland and the Netherlands

A wider study undertaken by the European Commission (2013) compares residential premiums associated with EPCs in five European countries: Austria, Belgium, France, Ireland, and the UK. The sales price effects from increased energy efficiency are significant and positive in all cases apart from Oxford in the UK, although this may be due to age of dwellings being an omitted variable in the UK dataset (Figure 2). A one-letter improvement on the horizontal axis in Figure 2 signifies moving up the energy performance scale. For instance, in the Irish Building Energy Rating, a B rating indicates energy use per year between $50 \mathrm{kwh} / \mathrm{m}^{2}$ to $125 \mathrm{kwh} / \mathrm{m}^{2}$ while an A rating implies energy use below $50 \mathrm{kwh} / \mathrm{m}^{2}$ per year, under the assumption of standard occupancy. Energy performance associated with each rating 
can be found on an Energy Performance Certificate. In this study, on average, the positive residential price effect of moving up the scale by one-letter or equivalent ranges between $1 \%$ to $11 \%$, depending on the location.

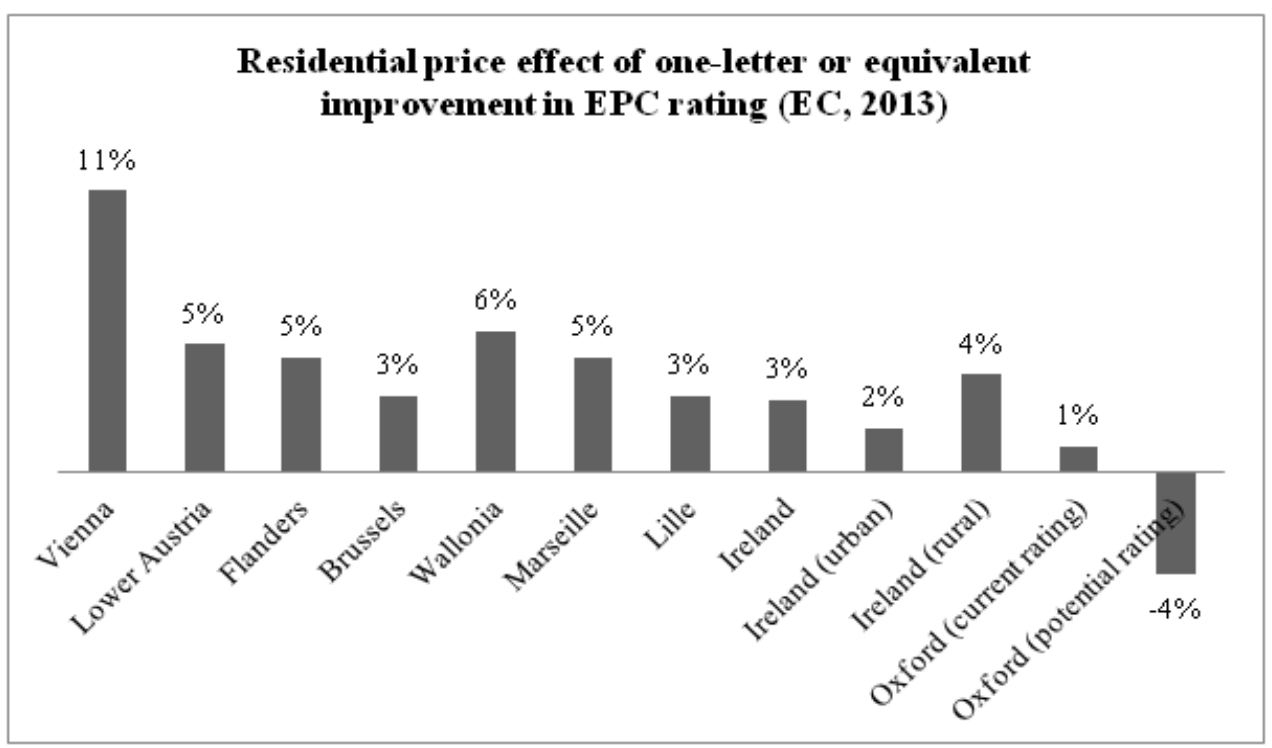

Figure 2: Residential price effect of one-letter or equivalent improvement in EPC rating (EC, 2013a)

Further studies in Europe, Australia, the United States, and Singapore confirm findings that residential buyers are willing to pay a premium for energy efficient housing (Australian Bureau of Statistics 2008; Cajias \& Piazolo 2013; Cerin et al. 2014; DECC 2013; Deng et al. 2013; Dinan \& Miranowski 1989; Fuerst et al. 2013; Högberg 2013; Kahn \& Kok 2012), although some papers have produced more mixed results (Amecke 2012; Murphy 2014; Walls et al. 2013; Yoshida \& Sugiura 2010).

\section{Data}

Information on 2,792 residential properties for sale in the Dublin region from January 2009 to June 2014 is used in this analysis, sourced from daft.ie, the largest real estate website in Ireland capturing $90 \%$ of all properties advertised on the market. ${ }^{1}$ The daft.ie data contains information on the sales price, location (split by 25 regions in Dublin), time period of advertisement, housing type (apartment, detached, terraced, etc.), size (in square metres), and age. For the purposes of this study, the data was limited to properties between the prices of $€ 30,000$ and $€ 2$ million, $25 \mathrm{~m}^{2}$ and $400 \mathrm{~m}^{2}$, have three floors or less, and contain up to six bedrooms. List prices are used as opposed to the price at point of sale due to data constraints. This approach could lead to bias in estimates of efficiency label effects if list prices behave significantly different from sales prices over time or across dwelling types and the differences are correlated with energy efficiency characteristics. However, in the absence of actual sales prices, previous analysis show that, where controls for market conditions are included, appraised values are a

\footnotetext{
${ }^{1}$ http://www.daft.ie/about/ [Accessed 12 August 2014]
} 
reliable proxy for transaction prices (Malpezzi 2003; Shimizu et al. 2012) and that the variation over time in asking prices and transaction prices in Ireland are highly correlated (Lyons 2013).

The information on the properties sold was matched by address with information from Ireland's Building Energy Ratings database. In Ireland, following the EU Directive on the Energy Performance of Buildings being passed into Irish law in 2006, Building Energy Ratings (BERs) were compulsory for any dwellings seeking planning permission, and since January 2009, for existing residences for sale or for rent. Equivalent to an energy performance certificate, the Irish BER is an objective measurement of the energy use for space and hot water heating, ventilation and lighting based on standard occupancy. Ratings range from $\mathrm{G}$ to $\mathrm{A} 1$ on a 15-point scale, where A-rated properties are the most energy efficient and will tend to have the lowest energy bills ceteris paribus (see Appendix 1 for sample Irish BER Certificate). Assessments are completed by BER Assessors registered with the Sustainable Energy Authority of Ireland (SEAI), the issuing authority for BER Certificates in Ireland. Certificates are accompanied by an Advisory Report which identifies the possible ways to improve the energy performance of a building. Once a BER is carried out, the Certificate is valid for 10 years, provided that no significant change is made to the building in that time (SEAI 2014a). In August 2014, there were 475,495 Domestic BERs on the Public Register (27\% of total private households in the country); $62 \%$ fell between a C1 and D2-rating, $13 \%$ were either A or B-rated, and 25\% were E-rated or lower (SEAI 2014b). Almost a third of total BERs on the register $(137,206)$ were issued for dwellings in the Dublin area.

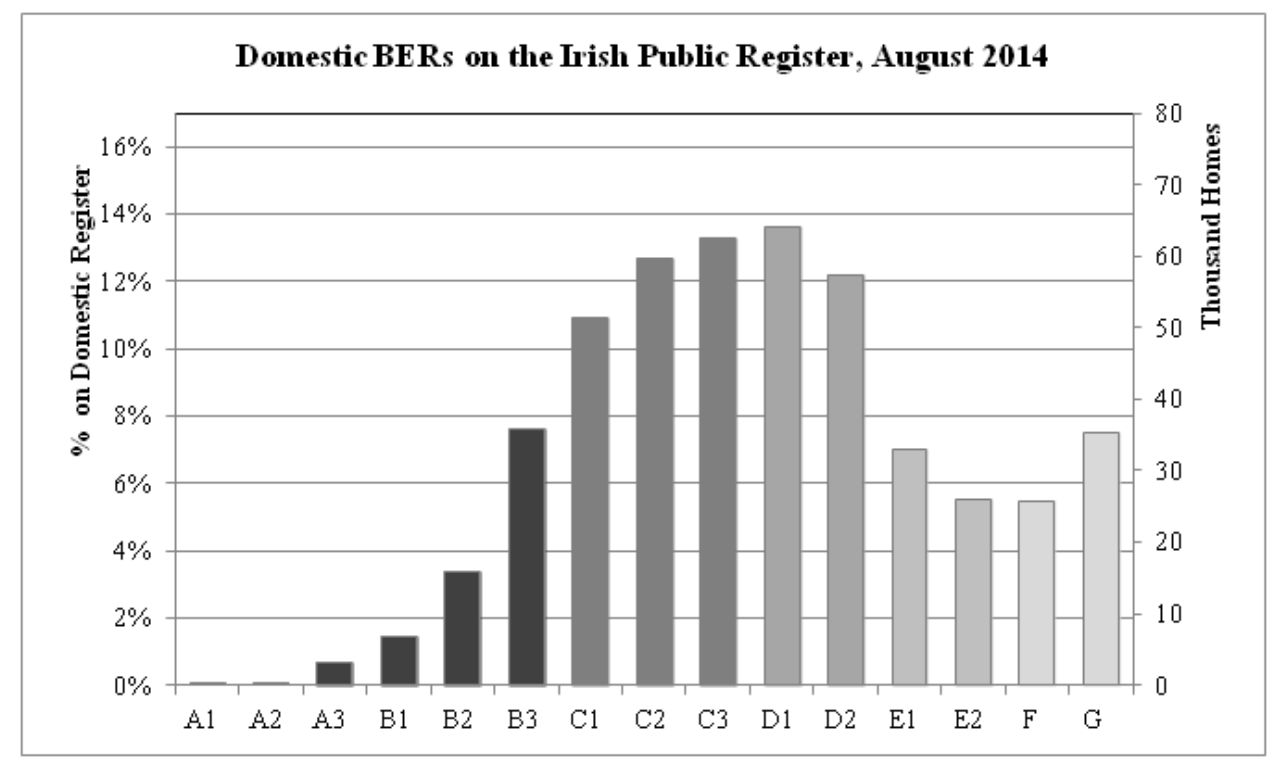

Figure 3: Domestic BERs on the Public Register (SEAI, 2014b)

The data in this study differs from the previous analysis undertaken in Ireland by Hyland et al. (2013) in several important ways. Rather than nationwide, this analysis looks in closer detail at the Irish capital city, Dublin, split between 25 districts. Data specific to smaller geographic areas enables a better approximation of neighbourhood effects and reduces the risk of heterogeneity at a county level, particularly prevalent in urban areas. The age of the building is included, removing the risk of omitted variable bias from this source. Hyland et al. (2013) did not have access to this information. Age of domestic buildings may be correlated with other characteristics such as size, dwelling type, and indeed BER rating. Given the implied correlation between BER rating and the age of a dwelling, the positive 
price effects associated with vintage housing may conceal negative impacts of poor energy performance. In addition, square metres provide a more accurate indicator of size than the number of bedrooms since room sizes can vary significantly both within and across buildings in the same category. A more homogenous group of properties in terms of size and value tends to improve the overall fit of a model, due to a lower range of error. As the disparity between observations in a data set is reduced, it is possible to obtain a more accurate guide to the underlying relationship between the characteristics and the price of a property. However, the results should be interpreted as those relating to Dublin, rather than an overall average for a country, which is provided by the wider cross section of data assessed in Hyland et al.

Finally, three different measures of energy efficiency are used: the Energy Performance Indicator (EPI), a continuous BER variable with a 15-point BER scale from A1 to G, and BER dummy variables indicating the premiums associated with each BER ranking compared to a $\mathrm{C} 1$-rating. The EPI is included on all BER Certificates as way of measuring energy performance relative to scale for a given year, calculated in the residential sector by dividing the total predicted energy consumption by total floor area and/or the occupation rate (SEAI 2014):

$E P I_{r}=k W h / m^{2} / y r$

Of the 2,870 dwellings observed, $7 \%$ have an A or B-rating, $58 \%$ fall under a C or D category, and $35 \%$ have a BER of E or lower. Compared to the national public register, the properties for sale in the Dublin area between 2009 and 2014 have a higher percentage of buildings in the lower rated categories (35\% compared to 25\%). Figure 4 displays the distribution of the total BERs in Dublin according to the SEAI database, compared to the sample of houses for sale with a BER. Figure 5 shows the distribution of properties in our sample by building type compared to all properties in the Dublin population (with and without BERs). Semi-detached housing is the most common type of dwelling in Dublin. However, apartments, terraced and detached housing are better represented in our sample due to more BERs associated with these categories on the market.

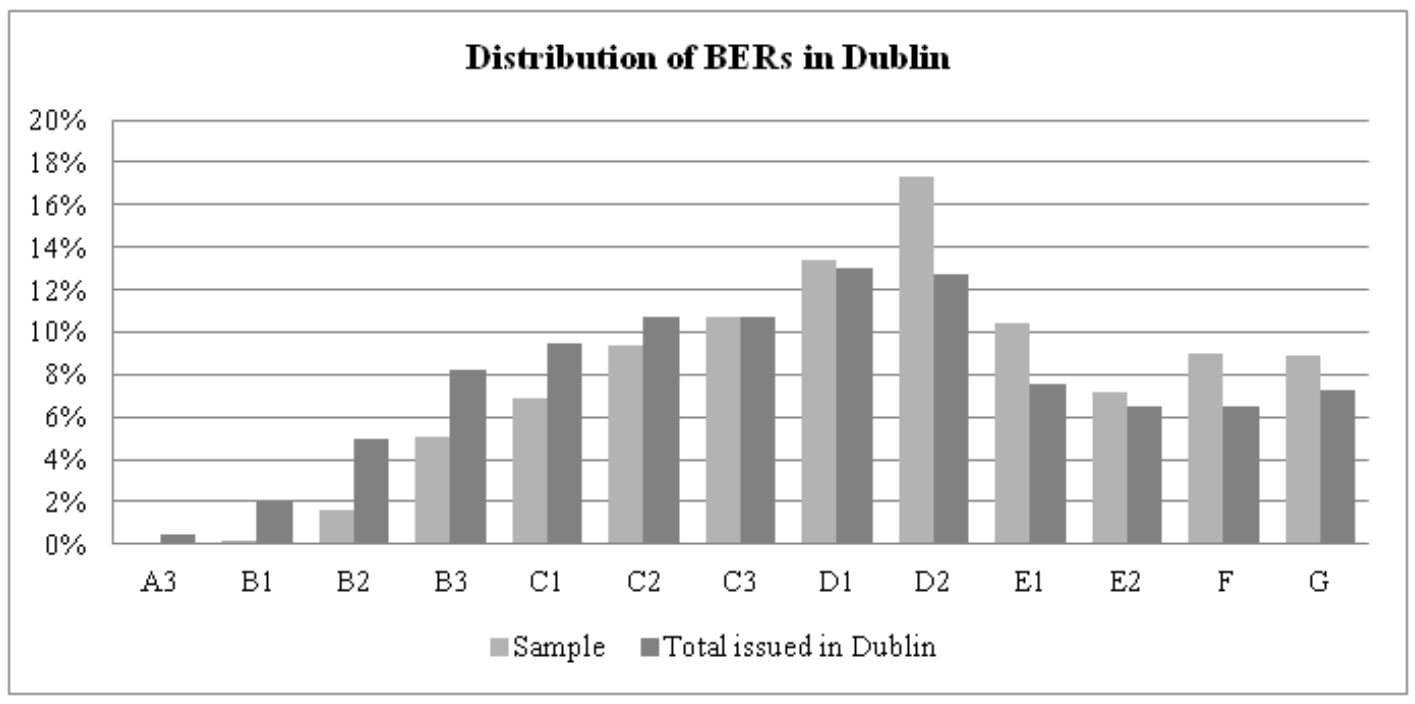

Figure 4: Distribution of BERs in Dublin 


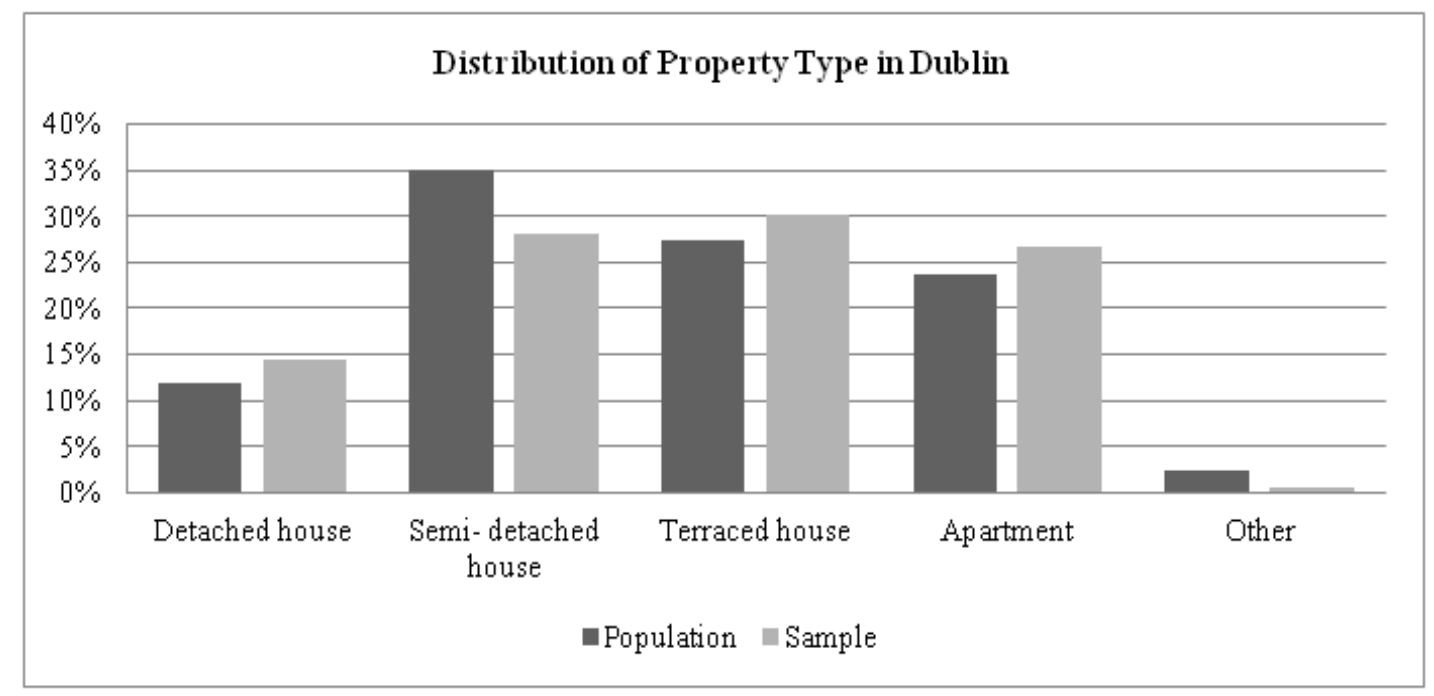

Figure 5: Distribution of Property Type in Dublin

\section{Methodology}

To estimate the value that residential users place on domestic energy efficiency, we use a technique known as hedonic regression, frequently applied in real estate and environmental analysis. This involves breaking down a property's value into its constituent parts; for example, location, building type, age, and size. Other factors that affect average housing prices such as the liquidity of the market, availability of supply, and population changes are assumed to be uncorrelated with building characteristics and therefore should not affect the statistical relationship between housing characteristics and price. However, depending on the purposes of the study, these factors are sometimes captured by a time variable. Early applications of hedonic valuation provided a method of predicting a price before it is known, for example, using a car's horsepower, design, etc. to appraise its worth (Court 1939). In the housing market, this is particularly useful when estimating pre sale property values or for the purposes of securing a loan. Later, hedonic methods were applied to quantify the value of individual attributes to a property's overall worth when the price is known (Nourse 1967; Ridker \& Henning 1967). The implicit value of the traits of a property are identified by regressing its revealed price (at point of sale or list price) on the attributes of a dwelling, statistically represented as the following:

$P=a_{0}+a_{1} X_{1}+a_{2} X_{2}+a_{3} X_{3}+\ldots+a_{n} X_{n}+e$

Where $P$ refers to the price of the dwelling, the $X_{i}$ 's represent the various characteristics of a property (age, size, etc.), $a_{i}$ indicates each of the characteristic's implied value, and $e$ is a random error term. While equation [2] assumes a linear function, other functional forms may be employed by transforming the relevant variables. For example if property value is not linear in the number of bedrooms, a squared term may be added to capture the diminishing marginal effects of size. As well as the attributes of a property $(x)$, the location $(n)$ and the energy rating $(c)$ are also included, such that:

$P=f(x, n, c)+e$

In addition to structural differences between buildings, a spatial or location variable enables the inclusion of a fixed effect associated with each neighbourhood that influence purchasing decisions. By including all the traits assumed to influence a property's price it is possible to estimate people's 
willingness to pay for individual features when its characteristics change. At its most basic level, given two similar properties in the same locality with different energy ratings, the difference in price indicates people's willingness to pay for increased energy efficiency.

\section{Results}

Table 1 presents the results for the hedonic price model relating the sales price of residences in Dublin $(n=2792)$ to their efficiency rating, building type, age, location, and time period of advertisement. Energy efficiency is measured by an Energy Performance Indicator (EPI) in model 1 and 2, a continuous BER scale in model 3, and a categorical variable in model 4.

The results show that energy efficiency has a significant, positive relationship with sales prices in Dublin's residential market. In the first instance, a 50-point improvement in the EPI is associated with a $1.5 \%$ higher list price. This matches findings from the European Commission (2013a). In the Flanders area of Belgium, a 50-point improvement in the CPEB metric (the Belgian equivalent of the Irish EPI) is associated with a $2.15 \%$ increase in sales price of homes and, narrowing the analysis to the capital city, Brussels, a 50-point CPEB improvement led to a $1.45 \%$ increase in price.

In the second model, we have transformed the EPI functional form from linear to logs to provide an interpretation of the relationship between EPI and price in terms of percentage rather than a unit change in EPI. The coefficient indicates that a $10 \%$ improvement in the EPI is associated with a $0.87 \%$ increase in Dublin property list prices, ceteris paribus. In terms of the BER, including a continuous 15point BER scale in model 3 yields a list price increase of $1 \%$ for every one-point improvement in the BER scale. This is consistent with Hyland et al. (2013) where each rating decline was associated with a reduction in price of $1.3 \%$. For the most part, model 4 produces statistically insignificant results, probably indicating that our sample is too small to segment this variable so finely. However, the signs roughly conform to expectations.

To test whether the value premium associated with residential efficiency is sensitive to the economic cycle, additional models were also run which included annual EPI interaction terms in model 1 and annual BER interaction terms in model 3. The inclusion of yearly interaction terms for the EPI and the BER test the hypothesis that the relationship between energy efficiency and price is dependent upon the year of advertisement. However, the results for the interaction terms were statistically insignificant suggesting that energy efficiency in the Dublin housing market was not any more (or less) prized in 2014 than in 2009 or 2010 when the Irish economy was in a deep recession.

The regression results also show that detached homes sell at a price premium, size has a significant, positive impact on price, and older buildings, particularly those built in the 1920s and pre1900 have the highest price premiums compared to newer builds from the 1990s. Location variables are excluded from the results table but are used to control for the effect of locality on housing price and displayed the expected price effects depending on the desirability of different areas.

A further insight from the analysis is that it is important to include controls for the age of the dwelling when modelling the value of residential energy efficiency. Omitting age effects leads to a downward bias in the estimated BER effects. Figure 6 charts the coefficient for the decade a house was built. Compared to Model 1, a model with no treatment of energy efficiency shows smaller vintage premia, indicative of correlation between the EPI and age, with the bias increasing the earlier the vintage. We can deduce, therefore, that in previous analysis lower BER properties were also likely to be of an older vintage and, according to the results, more valuable, introducing a downward bias to our coefficient. Thus, in older properties with poor BER ratings, the discounting effect may have been underestimated. 
Table 1: Hedonic Model Results

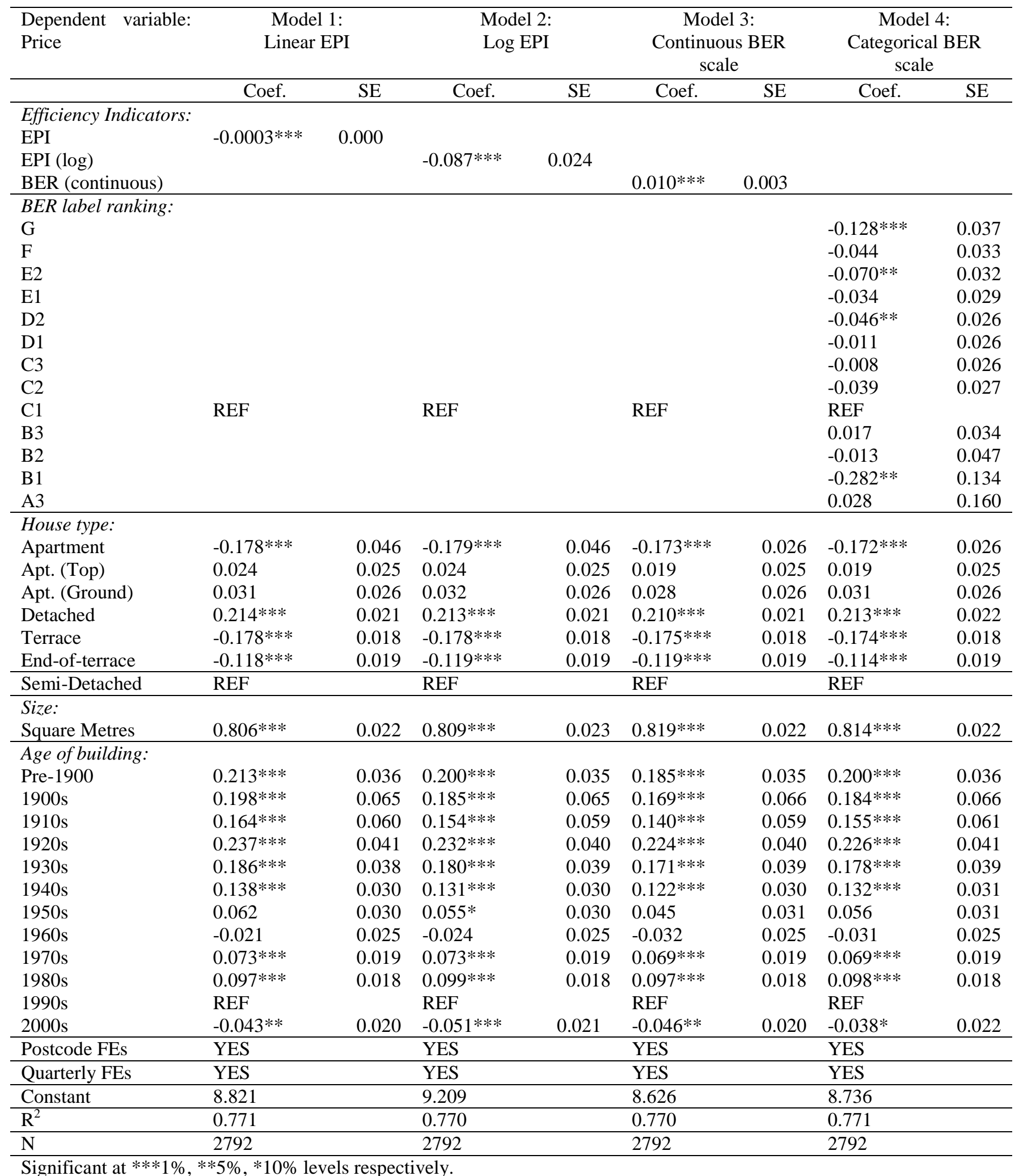




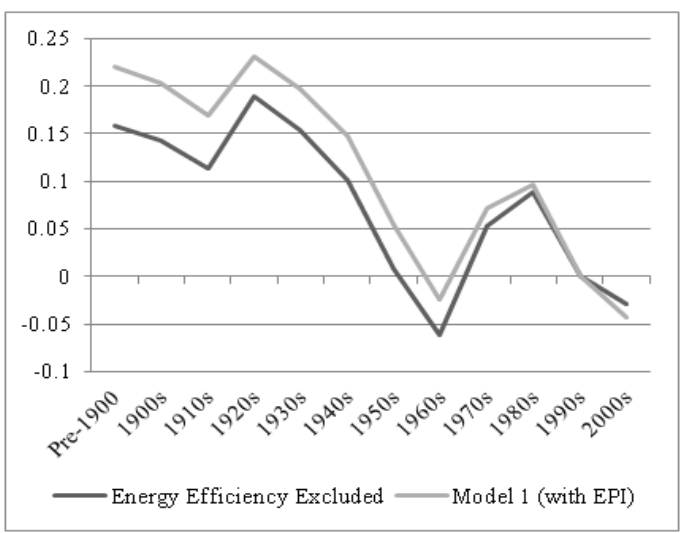

Figure 6: Coefficient on age of property, with and without an efficiency explanatory variable

One shortcoming of the data available to us was that not all properties in our dataset included a BER rating when advertising their property. We do not observe the BERs of those who did not advertise it. If there are unobserved characteristics (e.g. some aspect of dwelling quality) affecting both the decision whether to advertise the BER and the value of the dwelling, this selection bias could distort the estimated values for efficiency found by our models. For instance, there is evidence from Canada of participants in energy programmes replacing windows for the cosmetic rather than the energy saving benefits which may affect both decision to advertise the energy performance of a building and the value of a property (Persram 2011). Hyland et al. (2013) use a Heckman selection model to account for this possibility but ultimately find no correlation between the error terms in the selection and outcome equations (i.e. the decision to advertise BER was not correlated with unobserved factors influencing price) and obtained similar results using both the OLS and Heckman approach. We have not identified a suitable exclusion restriction to enable us to try this approach using the dataset in this paper, but it is worth considering for the future.

\section{Conclusions}

The results from our model show that energy efficiency has a positive and significant effect on residential property in the Dublin market. An increase by one-point in the BER is associated with $1 \%$ higher list prices, holding all other variables constant. This is consistent with the national estimate for Ireland in Hyland et al. (2013), which was based on less detailed location data and excluded the age of the building. Modelling efficiency on a continuous scale using the Energy Performance Indicator shows a $1.5 \%$ higher list price with every 50-point improvement in the EPI, producing estimates that are consistent with a related study in Brussels (EC 2013a). These results suggest that there is a willingness to pay for greater efficiency when buying a home. Since investing in energy efficiency can involve a significant upfront financial cost, initial investment may be offset if the value of efficiency is considered by potential buyers and captured in the selling price. In addition to expanding the geographic and temporal scope of analysis, further research could include a comparison of the price premiums derived here, and a range of potential savings and investment scenarios associated with increasing a building's EPI or BER.

\section{Acknowledgements}

We are grateful for funding from the Sustainable Energy Authority of Ireland and the ESRI Energy Policy Research Centre. The usual disclaimer applies. 


\section{Appendix 1: Sample Building Energy Rating Certificate}

\section{Building Energy Rating (BER)}

Name of House,

Street Name One, Street Name Two.

Town name One, Town Name Two.

County name One, County name Two,

The Building Energy Rating (BER) is an indication of the energy performance of this dwelling. It covers energy use for space heating, water heating.

ventilation and lighting, calculated on the basis of standard occupancy. It is expressed as primary energy use per unit floor area per year $\left(\mathrm{kWh} / \mathrm{m}^{2} / \mathrm{yr}\right)$.

$\begin{array}{ll}\text { BER Number: } & \text { XXXXXXXXXXX } \\ \text { Date of Issue: } & \text { Day Month Year } \\ \text { Valid Until: } & \text { Day Month Year } \\ \text { BER Assessor No.: } & \text { XXXX } \\ \text { Assessor Company No.: } & \text { XXXXX }\end{array}$
BER Assessor No:

' $A$ ' rated properties are the most energy efficient and will tend to have the lowest energy bills.

\section{Building Energy Rating}

$\mathrm{kWh} / \mathrm{m}^{2} / \mathrm{yr}$

MOST EFFICIENT
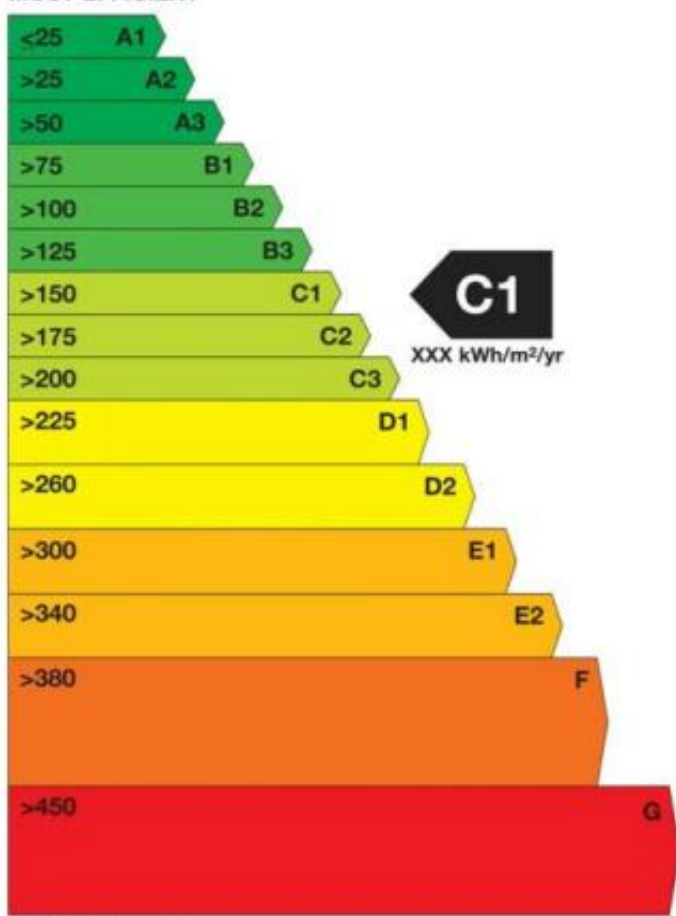

Carbon Dioxide $\left(\mathrm{CO}_{2}\right)$ Emissions Indicator $\mathrm{kgCO}_{2} / \mathrm{m}^{2} / \mathrm{yr}$

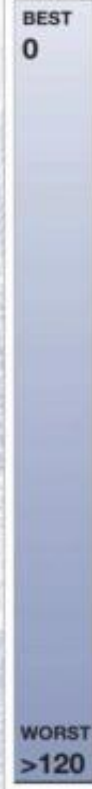

The less $\mathrm{CO}_{2}$ produced the less the dwelling contributes to global warming.

IMPORTANT: This BER is calculated on the basis of data provided to and by the BER Assessor, and using the version of the assessment software quoted above. A future BER assigned to this dwelling may be different. as a result of changes to the dwelling or to the assessment software. 


\section{Appendix 2: Correlation Matrix for continuous variables}

\begin{tabular}{|l|l|l|l|l|}
\hline & price & size_sqm & ber_epi & age_years \\
\hline price & 1 & & & \\
\hline size_sqm & 0.5146 & 1 & & \\
\hline ber_epi & -0.163 & -0.3453 & 1 & \\
\hline age_years & -0.0063 & -0.168 & 0.636 & 1 \\
\hline
\end{tabular}

\section{References}

Amecke, H., 2012. "The impact of energy performance certificates: a survey of German homeowners." Energy Policy 46: 4-14.

Allcot, H. and M. Greenstone. 2012. "Is there an Energy Efficiency Gap?" Journal of Economic Perspectives, 26 (1): 3-28

Australian Bureau of Statistics. 2008. Energy Efficiency Rating and House Price in the ACT. Department of the Environment, Water, Heritage and the Arts, Canberra.

Banfi, S., Farsi, M., Filippini, M. and M. Jakob. 2008. "Willingness to pay for energy saving measures in residential buildings." Energy Econ. 30 (2): 503-516.

Buildings Performance Institute Europe (BPIE), 2014. "Energy Performance Certificates across the EU A mapping of national approaches."

http://bpie.eu/uploads/lib/document/attachment/81/BPIE_Energy_Performance_Certificates_EU_mappi ng_-_2014.pdf

Brounen, D. and N. Kok. 2011. "On the economics of energy labels in the housing market." J. Environ. Econ. Manag. 62 (2): 166-179.

Cajias,M. and D. Piazolo. 2013. "Green performs better: Energy efficiency and financial return on buildings.” Journal of Corporate Real Estate. 15(1): 53-72.

Cerin, P., Hassel, L. and N. Semenova. 2014. "Energy Performance and Housing Prices." Sustainable Development Working Paper

Chegut, A., Eichholtz, P. and N. Kok. 2011. The value of green buildings: new evidence from the United Kingdom. Paper presented at the International AREUEA Meeting, Rotterdam, Netherlands 
Court, A. 1939. "Hedonic price indexes with automotive examples." In: The Dynamics of Automobile Demand. General Motors Company, New York.

Deng, Y., Li, Z. and J.M. Quigley. 2011. "Economic Returns to Energy-Efficiency Investments in the Housing Market; Evidence from Singapore.” Regional Science and Urban Economics, 42 (3): 506-515

Department of Energy and Climate Change (UK). 2013. An Investigation of the Effect of EPC Ratings on House Prices.

https://www.gov.uk/government/uploads/system/uploads/attachment_data/file/207196/20130613__Hedonic_Pricing_study___DECC_template_2_.pdf

Dinan, T.M. and J.A. Miranowski. 1989. "Estimating the implicit price of energy efficiency improvements in the residential housing market: a hedonic approach.” J. Urban Econ. 25 (1): 52-67.

Eichholtz, P., Kok, N. and J.M. Quigley. 2010. "Doing well by doing good? Green office buildings." Am. Econ. Rev. 100 (5): 2492-2509.

Eichholtz, P., Kok, N. and J.M. Quigley. 2013. “The economics of green building.” Rev. Econ. Stat. 95 (1): 50-63.

European Commission (EC). 2010. DIRECTIVE 2010/31/EU OF THE EUROPEAN PARLIAMENT AND OF THE COUNCIL (Recast). http://eur-lex.europa.eu/legalcontent/EN/TXT/PDF/?uri=CELEX:32010L0031\&from=EN

European Commission (EC). 2013a. "Energy performance certificates in buildings and their impact on transaction prices and rents in selected EU countries." EC, Brussels.

http://ec.europa.eu/energy/efficiency/buildings/doc/20130619-

energy_performance_certificates_in_buildings.pdf

European Commission (EC). 2013b. "Financial support for energy efficiency in buildings." EC, Brussels.http://ec.europa.eu/energy/efficiency/buildings/doc/report_financing_ee_buildings_com_2013 225_en.pdf

Fuerst, F. and P. McAllister. 2011a. "The impact of Energy Performance Certificates on the rental and capital values of commercial property assets.” Energy Policy 39 (10): 6608-6614.

Fuerst, F. and P. McAllister, P. 2011b. "Green noise or green value? Measuring the effects of environmental certification on office values.” Real Estate Econ. 39 (1): 45-69.

G8 Information Centre, 2015. Leaders' Declaration: G7 Summit. Schloss Elmau, Germany, June 8, 2015. http://www.g8.utoronto.ca/summit/2015elmau/2015-G7-declaration-en.html

Gillingham, K., Newell, R. and K. Palmer. 2009. “Energy Efficiency Economics and Policy.” Annual Review of Resource Economics, Annual Reviews 1(1): 597-620. 
Gillingham, K., Harding, M. and D. Rapson. 2012. "Split Incentives in Residential Energy Consumption" Energy Journal 33 (2): 37-62.

Högberg, L. 2013. "The impact of energy performance on single-family home selling prices in Sweden" Journal of European Real Estate Research 6(3): 242-261.

Hyland, M., Lyons, R.C. and S. Lyons. 2013. "The value of domestic building energy efficiency evidence from Ireland.” Energy Economics 40: 943-952.

International Energy Agency (IEA). 2010. "Energy Performance Certification of Buildings - A policy tool to improve energy efficiency." https://www.iea.org/publications/freepublications/publication/buildings_certification.pdf

International Energy Agency (IEA). 2013. " $\mathrm{CO}_{2}$ Emissions from Fuel Combustion - Highlights.” http://www.iea.org/publications/freepublications/publication/co2emissionsfromfuelcombustionhighlight $\underline{\text { s2013.pdf }}$

Kahn, M.E. and N. Kok. 2012. "The value of green labels in the Californian housing market." http://www.usgbc.org/sites/default/files/ValueofGreenHomeLabelsStudy_July2012.pdf

Lyons, R.C. 2013. "Price signals and bid-ask spreads in an illiquid market: the case of residential property in Ireland, 2006-2011.” http://ssrn.com/abstract=2205742

Malpezzi, S. 2003. "Hedonic pricing models: a selective and applied review." In: O'Sullivan, Tony, Gibb, Kenneth (Eds.), Housing Economics and Public Policy: Essays in honour of Duncan Maclennan, 2003. Blackwell.

McLean, A., Horvath, A. and H. Janos Kiss. 2013. "How does an increase in energy efficiency affect housing prices? A Case Study of a Renovation.” In: Book of proceedings: 20th Annual Conference of the European Real Estate Society. ÖKK-Verlag, Vienna, pp. 39-55. ISBN 978-3-85437-323-0

Miller, N., Spivey, J. and A. Florance. 2008. “Does Green Pay Off?” Journal of Real Estate Portfolio Management 14 (4)

Murphy, L. 2014. “The Influence of the Energy Performance Certificate: The Dutch Case.” Energy Policy 67: 664-672

Nourse, H. O. 1967. “The Effect of Air Pollution on House Values.” Land Economics, 43: 181-189

Persram, S. 2011. "Property assessed payments for energy retrofits - recommendations for regulatory change and optimal program features." David Suzuki Foundation.

http://www.davidsuzuki.org/publications/downloads/2011/Property-Assessed-Payments-for-EnergyRetrofits-recommendations-1.pdf

Pivo, G. and J.D. Fisher. 2010. "Income, Value, and Returns in Socially Responsible Office Properties." Journal of Real Estate Research 32 (3): 243-270. 
Popescu, D., Bienert, S., Schutzenhofer, C. and R. Boazu. 2012. "Impact of Energy Efficiency Measures on the Economic Value of Buildings." Applied Energy 89: 454-463.

Ridker, R. and J. Henning. 1967. "The determinants of residential property values with special reference to air pollution." The Review of Economics and Statistics 49: 246-257.

Shimizu, C., Nishimura, K.G. and T. Watanabe1. 2012. "House prices from magazines, realtors, and the Land Registry". In: Bank for International Settlements (Ed.), Property markets and financial stability: 29-38.

Sustainable Energy Authority of Ireland. 2014. "BER information leaflet" http://www.seai.ie/Your_Building/BER/Your_Guide_to_Building_Energy_Rating.pdf

Sustainable Energy Authority of Ireland. 2014. "BER Statistics - Domestic BERs Dashboard." http://www.seai.ie/Your_Building/BER/BER_FAQ/FAQ_BER/General/Domestic-BERs-Dashboard.pdf

The European Parliament the Council of the European Union, 2010a. "EU Energy Efficiency Policy Achievements and Outlook." http://www.europarl.europa.eu/RegData/etudes/etudes/join/2010/451482/IPOLITRE_ET(2010)451482_EN.pdf

The European Parliament the Council of the European Union, 2010b. Directive 2010/31/EU on the energy performance of buildings (recast). Off. J. Eur. Union 53, 153 (Legislation).

United Nations Framework Convention on Climate Change (UNFCCC), 2012. "Kyoto Protocol." http://unfccc.int/kyoto_protocol/items/2830.php

Walls, M., Palmer, K. and T. Gerarden. 2013. "Is Energy Efficiency Capitalized into Home Prices? Evidence from Three US Cities.” Resources for the Future Discussion Paper. http://www.rff.org/RFF/Documents/RFF-DP-13-18.pdf

Wiley, J.A., Benefield, J.D. and K.H. Johnson. 2008. "Green design and the market for commercial office space.” J. Real Estate Financ. Econ. 41: 228-243.

Yoshida, J. and A. Sugiura. 2010. "Which "Greenness" is valued? Evidence from Green Condominiums in Tokyo." Munich Personal RePEc Archive. http://mpra.ub.unimuenchen.de/23124/1/MPRA_paper_23124.pdf 